\title{
Effects of green coffee extract supplementation on anthropometric indices, glycaemic control, blood pressure, lipid profile, insulin resistance and appetite in patients with the metabolic syndrome: a randomised clinical trial
}

\author{
Hanieh Roshan ${ }^{1}$, Omid Nikpayam ${ }^{1}$, Meghdad Sedaghat ${ }^{2}$ and Golbon Sohrab ${ }^{3 *}$ \\ ${ }^{1}$ Clinical Nutrition and Dietetics Department, Faculty of Nutrition Sciences and Food Technology, Shabid Beheshti University \\ of Medical Sciences, 1981619573, Tehran, Iran \\ ${ }^{2}$ Imam Hossein Hospital, Shahid Beheshti University of Medical Sciences, 1981619573, Tehran, Iran \\ ${ }^{3}$ Internal Medicine Department, Shabid Beheshti University of Medical Sciences, 1985717443, Tehran, Iran
}

(Submitted 12 July 2017 - Final revision received 20 September 2017 - Accepted 23 October 2017-First published online 8 January 2018)

\section{Abstract}

This study was conducted to elucidate the effects of decaffeinated green coffee bean extract (GCE) on anthropometric indices, glycaemic control, blood pressure, lipid profile, insulin resistance and appetite in patients with the metabolic syndrome (Mets). Subjects were randomly allocated to consume $400 \mathrm{mg}$ GCE or placebo capsules twice per d for 8 weeks. Both groups were advised to follow an energy balanced diet. After GCE supplementation, systolic blood pressure (SBP) significantly reduced compared with the placebo group ( -13.76 (SD 8.48 ) $v$. -6.56 (sD 9.58) $\mathrm{mmHg}, P=0 \cdot 01)$. Also, GCE treatment significantly reduced fasting blood glucose (FBS) $(-5 \cdot 15$ (SD $60 \cdot 22) v .29 \cdot 42(\mathrm{sD} 40 \cdot 01) \mathrm{mg} / \mathrm{dl}$ $(-0.28$ (sD 3.34) v. $1.63(\mathrm{sD} 2.22) \mathrm{mmol} / \mathrm{l}) ; P=0.03)$ and homoeostatic model of assessment of insulin resistance in comparison to placebo $(-1.41$ (sD 3.33) v. $1.23(\mathrm{sD} 3.84), P=0.02)$. In addition, waist circumference $(-2.40(\mathrm{sD} 2.54) v .-0.66(\mathrm{sD} 1.17) \mathrm{cm}, P=0.009)$ and appetite score $(-1.44$ (SD 1.72) $v \cdot-0.2$ (sD 1.32), $P=0.01$ ) of the individuals supplemented with GCE indicated a significant decline. Besides, weight and BMI reduction in the intervention group was almost twice as much as the placebo group; however, this discrepancy was marginally significant (weight: -2.08 (SD 2.11$) v .-0.92$ (SD 1.30$) \mathrm{kg}, P=0.05$ ). No difference was observed in terms of glycated Hb (HbA1c) percentage and lipid profile parameters between the two groups. To sum up, GCE administration had an ameliorating effect on some of the Mets components such as high SBP, high FBS and Mets main aetiological factors including insulin resistance and abdominal obesity. Furthermore, GCE supplementation could reduce appetite level.

Key words: Green coffee bean extract: Chlorogenic acid: Blood pressure: Weight: Fasting blood glucose: Lipid profile: Insulin resistance

The metabolic syndrome (Mets) is characterised by the coexistence of risk factors predisposing to type 2 diabetes mellitus (T2DM) and CVD. It can contribute to a 5-fold increase in the risk of T2DM and double the risk of developing CVD over the next 5-10 years ${ }^{(1)}$. These underlying risk factors which are deemed as Mets components include central obesity, hyperglycaemia, hypertension, raised serum TAG and decreased HDLcholesterol $^{(2)}$. It is a rampant and burgeoning health issue globally that affects about $20-25 \%$ of the world's adult population ${ }^{(3)}$. Several elements are implicated in the development of the Mets but insulin resistance and abdominal obesity have been identified as the major aetiological factors ${ }^{(3)}$. As chemical drugs have adverse side effects ${ }^{(4)}$ and no single treatment has been identified for treating the Mets, there has been a growing interest in finding natural substances to curb the Mets ${ }^{(5)}$.
Coffee is one of the most widely consumed beverages around the world ${ }^{(6)}$. It is rich in phenolic compounds which are acknowledged as protective agents against chronic degenerative diseases ${ }^{(7)}$. There is mounting evidence from epidemiological studies that coffee consumption correlates with a lower risk of developing the Mets ${ }^{(6)}$ and $\mathrm{T}_{2} \mathrm{DM}^{(8)}$. Chlorogenic acids (CGA) are the major phenolic compounds in coffee. In fact, CGA which are esters of certain cinnamic acids (caffeic, ferulic or coumaric acid) with quinic acid naturally occur in many plant foods ${ }^{(9)}$ but coffee beans are their primary dietary source. As a substantial amount of CGA are lost during the roasting process, green coffee (GC) beans are a richer source of $\mathrm{CGA}^{(10)}$. It has been extensively demonstrated in animal studies that CGA possess anti-diabetes ${ }^{(8)}$, anti-obesity ${ }^{(11)}$ and anti-lipidaemic properties $^{(11,12)}$ and also could exert ameliorating effects on

Abbreviations: CGA, chlorogenic acids; DBP, diastolic blood pressure; DGCE, decaffeinated GCE; FBS, fasting blood glucose; GC, green coffee; GCE, green coffee bean extract; HbA1c, glycated Hb; HFD, high-fat diet; HOMA-IR, homoeostatic model assessment; Mets, metabolic syndrome; SBP, systolic blood pressure; TC, total cholesterol.

* Corresponding author: G. Sohrab, fax +9821 22360660, email golbonsohrab@yahoo.com 
insulin resistance ${ }^{(13)}$. In addition, CGA have been reported to be capable of reducing blood pressure ${ }^{(14,15)}$ and postprandial glucose absorption in human studies ${ }^{(16)}$

GC has been proposed to have the potentiality to prevent from the Mets ${ }^{(17)}$ and T2DM ${ }^{(18)}$. Despite some null findings ${ }^{(19)}$, some studies have demonstrated alleviating effects of GC on some of the Mets components such as blood pressure ${ }^{(20-22)}$, blood glucose $\mathrm{e}^{(17,23,24)}$, lipid profile $\mathrm{e}^{(7,23,24)}$ and also main Mets aetiological factors including insulin resistance (17,24,25) and obesity $^{(23,24,26,27)}$. For instance, a recent study investigated effects of high-fat diet (HFD) ingestion with 50, 100 or $200 \mathrm{mg} / \mathrm{kg}$ green coffee bean extract (GCE) for 6 weeks on HFD-induced obese mice. In this study, a significant reduction in body weight gain, fat mass, glucose, TAG, LDL and total cholesterol (TC) concentration and significant elevation in HDL-cholesterol was seen mainly with 100 or $200 \mathrm{mg} / \mathrm{kg} \mathrm{GCE}$ plus HFD compared with HFD alone ${ }^{(23)}$. A cross-over study compared consumption of $40 \mathrm{~g} / \mathrm{d}$ of green or black coffee in eighteen healthy subjects for 2 weeks. A significant decrease was seen regarding systolic blood pressure (SBP), body weight and BMI with GC compared with black coffee. Also, diastolic blood pressure (DPB), waist circumference and abdominal fat reduced after both interventions ${ }^{(20)}$. In a clinical trial conducted on 117 mildly hypertensive males, 93 and $185 \mathrm{mg}$ GCE could significantly reduce SBP and DBP after $28 \mathrm{~d}$ compared with placebo. However, this low dose GCE could not improve lipid profile or weight of the subjects ${ }^{(22)}$. Also, a non-blinded and none-randomised clinical trial on fifteen healthy patients taking $600 \mathrm{mg}$ (three capsules of $200 \mathrm{mg}$ ) of decaffeinated GCE (DGCE) for $40 \mathrm{~d}$ indicated decreased postprandial glycaemia and 3 pounds weight loss ${ }^{(28)}$. One contradictory animal study which was conducted on mouse model of the Mets, exhibited no improvement in body weight, glucose tolerance and insulin resistance after a 12 week ingestion of $0.5 \%(\mathrm{w} / \mathrm{w})$ GCE plus HFD compared with a HFD-fed group ${ }^{(19)}$

Data concerning GCE impacts on Mets components are rather inconsistent. Most of the previous studies have been conducted on animal models and have assessed CGA effects rather than GCE impacts. Interventional studies regarding GCE effects are scarce and they have mostly limitations such as being nonrandomised, non-blinded and not placebo-controlled or having low sample size and duration. Up to our knowledge, no clinical trial has been conducted on GCE effects on Mets patients so far. Thus, we aimed to carry out this clinical trial to elucidate GCE effects on anthropometric indices, glycaemic control, insulin resistance, blood pressure, lipid profile and appetite in patients with the Mets.

\section{Methods}

\section{Green coffee extract characteristics and analytical assays}

The DGCE and placebo capsules were provided by Arjuna Natural Extracts Ltd. The GCE was standardised with $46.45 \%$ total CGA by HPLC. The total CGA identified comprised of 5-caffeoylquinic acid (5-CQA), 3-caffeoylquinic (3-CQA), 4-caffeoylquinic acid, 3,4-dicaffeoylquinic acid, 3,5-dicaffeoylquinic acid, 4,5-dicaffeoylquinic acid, 3-feruloylquinic acid, 4-feruloylquinic acid and 5-feruloylquinic acid. 5-CQA and 3-CQA were the principal CGA which composed about 35-40\% and $10-15 \%$ of the total CGA content, respectively. The raw material (GC bean) to extract ratio was $6: 1$. Hence, each $400 \mathrm{mg}$ capsule of GCE was equal to $2400 \mathrm{mg}$ GC bean and contained $186 \mathrm{mg}$ of CGA. The total polyphenols percentage in the GCE supplements was $53.8 \%$. HPLC for measuring CGA content was performed by combining $25 \mathrm{mg}$ of sample or standard with $15 \mathrm{ml}$ of $70 \%$ methanol in a $25 \mathrm{ml}$ standard flask. Subsequently, the samples were injected into the HPLC system following filtering through a $0.2 \mu \mathrm{g}$ membrane. Moreover, phenolic compounds were measured by spectrophotometric method by mixing $2 \mathrm{ml}$ of $1 \mathrm{~N}$ Folin CioCalteu's reagent and $10 \mathrm{ml}$ of sodium carbonate solution with $2 \mathrm{ml}$ of dissolved sample or standard. Afterwards, UV absorbance was measured at $700 \mathrm{~nm}$ against water blank and the following calculation was used: total polyphenol= (sample absorbance $\times$ working standard weight $\times$ purity of working standard)/(working standard absorbance $\times$ sample weight).

The CGA rich extract was prepared by usage of alcohol and caffeine was removed from the extract by using chloroform. For preparing the extract, alcohol-water (70:30) is added to the powdered GC bean and it is stirred at the temperature of $45-55^{\circ} \mathrm{C}$ for $4 \mathrm{~h}$. The process is repeated twice. Afterwards, the solvent portion is distilled off the alcohol and the aqueous layer is extracted with chloroform to eliminate caffeine. Thereafter, chloroform portion is separated and the aqueous portion is filtered and vaporised by spray drying to produce the dry powder. Table 1 shows the analytical assays of the extract. Placebo capsules were composed of starch with no additives or excipients.

\section{Participants}

This study was a randomised, double-blind, placebo-controlled trial. Men and women aged between 18 and 70 years whom were diagnosed with the Mets and had BMI of over $25 \mathrm{~kg} / \mathrm{m}^{2}$ were chosen from the clients of Imam Hossein Hospital diabetes clinic in Tehran. The Mets was diagnosed according to the new International Diabetes Federation definition ${ }^{(3)}$ as having central obesity (waist circumference $>102 \mathrm{~cm}$ in men or $>88 \mathrm{~cm}$ in women) in conjunction with two of the following risk factors: fasting blood glucose (FBS) $>100 \mathrm{mg} / \mathrm{dl}(>5.55 \mathrm{mmol} / \mathrm{l})$, TAG $>150 \mathrm{mg} / \mathrm{dl} \quad(>1.69 \mathrm{mmol} / \mathrm{l}), \quad$ HDL-cholesterol $<50 \mathrm{mg} / \mathrm{dl}$ $(<1.29 \mathrm{mmol} / \mathrm{l})$ in women or $<40 \mathrm{mg} / \mathrm{dl}(<1.03 \mathrm{mmol} / \mathrm{l})$ in men, $\mathrm{SBP}>130 \mathrm{mmHg}$ and DBP $>85 \mathrm{mmHg}$. The subjects which met our exclusion criteria as insulin administration for controlling blood glucose, having hypo- or hyperthyroidism, renal failure, routine coffee consumption, pregnancy or breast-feeding, taking corticosteroids, hormone replacement therapy as taking

Table 1. Analytical assays of the green coffee bean extract

\begin{tabular}{lccl}
\hline Assay & Specification & Result & Method \\
\hline Total chlorogenic acid & $45-50 \%$ & $46.45 \%$ & HPLC \\
Total polyphenols & $50-55 \%$ & $53.8 \%$ & Spectrophotometer \\
Caffeine & $0-2 \%$ & $1.81 \%$ & HPLC \\
Excipients & None & Complies & In-house specification \\
\hline
\end{tabular}


oestrogen or progesterone, taking weight loss supplements or following unusual weight loss plans, cancer, experiencing cerebrovascular accident and other cognitive problems or chronic diseases that impaired their compliance were not included in the study. Also, the patients who altered the type or dose of the medications they used for controlling blood glucose, blood pressure or lipid profile were excluded. Moreover, if a patient had not consumed over $10 \%$ of the supplements, he or she was eliminated from the study. This was assessed by counting the number of capsules remained in the bottle of supplements at the follow-up visits at the 4 th and the 8th week of the study.

\section{Study design}

The procedure of the study was described for eligible clients of the diabetes clinic and a written informed consent was signed by the volunteers. A questionnaire regarding smoking status, present illnesses, drug history, prescribed medications, menopause status and duration of diabetes (if diabetic) was filled out by interviewing the volunteer patients. Subjects and investigators were blinded until the end of the study as the bottles of supplements were coded with A or B by the manufacturer before the study. Participants were stratified by sex and randomly allocated to the intervention or placebo group by stratified blocked randomisation method. Blocked randomisation was done with block sizes of four concealed in a container by one of the researchers. The blocks were composed of A and B characters representing bottles of capsules coded with A or B to ensure concealment. The other investigator randomly allocated the participants to one of the two groups. The patients were supposed to consume $400 \mathrm{mg}$ of GCE or placebo twice per $\mathrm{d}(800 \mathrm{mg} / \mathrm{d})$ with their main meals for $64 \mathrm{~d}$. A bottle of supplements containing sixty-four capsules, adequate for $32 \mathrm{~d}$, was given to both groups at the time of randomisation and the other bottle was given at the time of the 4th-week followup visit. All the subjects were instructed not to modify their physical activity and salt intake. In addition, a dietary plan with weight loss recommendations was handed to the participants of both groups to amend their nutritional habits. The proportion of macronutrients in the plan in relation to the total energy was $30 \%$ total fat, $18 \%$ protein and $52 \%$ carbohydrate. This study was approved by the ethics committee of National Nutrition and Food Technology Research Institute of Shahid Beheshti University of Medical Sciences and was registered at ClinicalTrials.gov ID: NCT02764957.

\section{Follow-up}

Subjects were followed by making phone calls every $15 \mathrm{~d}$ to ensure that they complied with the supplementation protocol. Moreover, a follow-up visit was arranged for each individual in the middle of the study at the 4 th week.

\section{Dietary assessment}

Dietary intake was assessed at baseline, at the 4th-week and at the end of the study using a 3 -d food record. The participants were instructed how to record their food and beverage intake for $3 \mathrm{~d}$ at each time. In order to distinguish the accurate portion sizes, the patients were interviewed to report their intake based on household measures. Subsequently, the portion sizes were converted to grams and analysed for energy and nutrients content using Nutritionist 4 software, that was modified using the national composition food tables ${ }^{(29)}$. Physical activity was assessed using the metabolic equivalent of task (MET) questionnaire ${ }^{(30)}$ at the beginning and at the end of the trial. Also, appetite score was assessed by means of simplified nutritional appetite questionnaire $(\mathrm{SNAQ})^{(31)}$ which was validated by Wilson et al. for assessing appetite and prediction of weight loss. It consists of four questions about level of appetite, amount of food eaten to feel full, taste of foods and number of meals consumed in a day, each with five responses. Scoring of the questionnaire was based on assigning score of $1-5$ to the first to fifth response, respectively. Sum of the scores of all questions were considered as the total appetite score. SNAQ score of 4-14, 15-20 and over 20 were assumed as low, moderate and high appetite level.

\section{Measurement of anthropometric parameters and blood pressure}

Weight, waist circumference, SBP and DBP of the subjects were measured and BMI was calculated at baseline and at the end of the intervention. Height was measured barefoot to the nearest $0.5 \mathrm{~cm}$ using a tape measure attached to the wall at baseline. Also, weight was measured with a precision of $100 \mathrm{~g}$, wearing light clothes, using Seca digital scale. In addition, waist circumference was measured to the nearest $0.5 \mathrm{~cm}$ approximately between the lower margin of the last rib and top of the iliac crest at the level of navel with a tape measure. BMI was calculated by dividing weight $(\mathrm{kg})$ by square of height $\left(\mathrm{m}^{2}\right)$. Also SBP and DBP were measured twice after a 10-min rest using Citizen digital blood pressure monitor in order to assess blood pressure with $1 \mathrm{mmHg}$ precision. The average of the two measurements was used for analysis.

\section{Measurement of biochemical parameters}

Following a 12-h fasting period, $10 \mathrm{ml}$ of venous blood sample was drawn from the subjects before and after the intervention. The glycated $\mathrm{Hb}$ (HbA1c) test was performed on the whole blood sample by means of Biosystem commercial kits (Biosystems) using chromatography method on the day of taking the blood samples. The blood serum was obtained by centrifugation at a rate of 2000 round per min and was aliquoted into microtubes. Afterwards, the serums were frozen at $-80^{\circ} \mathrm{C}$ until the time of conducting the experiments. Serum FBS, HDL-cholesterol, TC and TAG concentrations were measured by photometric enzymatic method by means of Pars Azmoon kits (Pars Azmoon). LDL-cholesterol concentration was calculated using Friedwald formula: $\mathrm{LDL}=\mathrm{TC}-\mathrm{HDL}-(\mathrm{TAG} / 5)$. Fasting insulin levels were assessed by Monobind Elisa kits (Monobind). Furthermore, insulin resistance was evaluated by homoeostatic model assessment (HOMA-IR) method using the following formula: HOMA-IR $=($ glucose $(\mathrm{mg} / \mathrm{dl}) \times$ insulin $(\mu \mathrm{IU} / \mathrm{ml})) / 405$ or $($ glucose $(\mathrm{mmol} / \mathrm{l}) \times$ insulin $(\mu \mathrm{IU} / \mathrm{ml})) / 22 \cdot 5^{(32)}$.

\section{Statistical analyses}

Statistical analyses were performed using the 21th version of SPSS Software. The Kolmogorov-Smirnov test was used to determine 
the normality of data distribution. Qualitative variables were compared between the groups by the $\chi^{2}$ test. For quantitative variables, the means of the two groups were compared by the independent $t$ test and changes within each group were analysed by the paired sample $t$ test. Also, repeated-measures ANOVA was applied to compare within subjects' dietary intake values of pretrial, middle of the trial and post-trial in each group. All the tests were two-tailed, and $P$ value of $<0.05$ was considered as the significance threshold. The quantitative variables are all expressed as means and standard deviations.

The minimum sample size estimated for each group was 20 at a power $(1-\beta)$ of $80 \%$ and significance level of 0.05 for a twoarm parallel study with two-tailed testing to detect a difference of $47 \mathrm{mg} / \mathrm{dl}(2.60 \mathrm{mmol} / \mathrm{l})$ in mean values of FBS with a pooled standard deviation of $53 \mathrm{mg} / \mathrm{dl}(2.94 \mathrm{mmol} / \mathrm{l})$, obtained from the study of Ebrahimi et al. ${ }^{(33)}$. The hypothesised Cohen's $d$ effect size calculated by dividing difference of means by pooled standard deviation was $0 \cdot 8$ according to the mentioned study ${ }^{(33)}$.

\section{Results}

From fifty subjects who were recruited in this trial (twenty-five in the intervention and twenty-five in the control group), forty-three individuals (twenty-one in the intervention and twenty-two in the control group) completed the study. Due to possibility of participant drop-out, the recruited sample ( $n$ 50) exceeded the calculated sample size ( $n$ 40). The reason why four persons withdrew the study in the intervention group was not consuming the supplements, having pruritis, getting stomachache and initiating insulin administration. Also, three individuals in the control group were excluded from the study due to not consuming the capsules. No major side effect was observed following taking GCE supplements. However, one of the patients who had stomachache history reported stomach irritation after consuming the capsules and dropped out of the study. Also, another patient reported dizziness which was resolved following increasing the time gap between the two doses taken per $\mathrm{d}$.

The flow chart of study participants is illustrated in Fig. 1. Out of the forty-three participants having the Mets, thirty-four persons $(79 \%)$ were diabetic, whereas the other nine patients (21\%) did not suffer from diabetes. Baseline characteristics including sex, smoking status, age, duration of diabetes, menopause status and medications used for controlling blood glucose, blood pressure and lipid profile were not significantly different between the two groups (Table 2). Moreover, physical activity (MET-h/d) of the participants in the two groups did not have a significant difference at baseline and after the study (Table 3). Energy and nutrients intake were not significantly different between the two groups (Table 3 ).

As expressed in Table 4, analysis indicated that SBP had significantly decreased within both groups compared with the baseline. However, SBP reduction in the intervention group was significantly more than the placebo group $(-13.76$ (SD 8.48) v. $-6.56(\mathrm{SD} 9.58) \mathrm{mmHg})(P=0.01)$ (effect size: -0.79 ; $95 \% \mathrm{CI}-1 \cdot 41,-0 \cdot 17)$. In addition, post-trial mean DBP values of the GCE group were significantly $7.6 \%$ lower than the placebo group (77.02 (sD 7.88) v. 83.36 (sD 11.02) mmHg) $(P=0.03)$. Also, within the intervention group, DBP at the end of the trial was significantly $4.6 \%$ less than the baseline (77.02 (SD 7.88) $v$. $80 \cdot 8$ (SD 9.56) $\mathrm{mmHg})(P=0 \cdot 02)$.

Changes of FBS were different between the groups as GCE treatment had significantly attenuated FBS compared with the placebo $(-5 \cdot 15(\mathrm{SD} 60 \cdot 22)$ v. $29 \cdot 42(\mathrm{sD} 40 \cdot 01) \mathrm{mg} / \mathrm{dl})(-0 \cdot 28$ (sD $3.34)$ v. $1.63(\mathrm{sD} 2 \cdot 22) \mathrm{mmol} / \mathrm{l})(P=0.03)$ (effect size: -0.67 ; $95 \%$ CI $-1.29,-0 \cdot 06)$. Furthermore, within the GCE group, fasting insulin levels had significantly diminished by $22 \%$ (12.94 (SD 5.96)

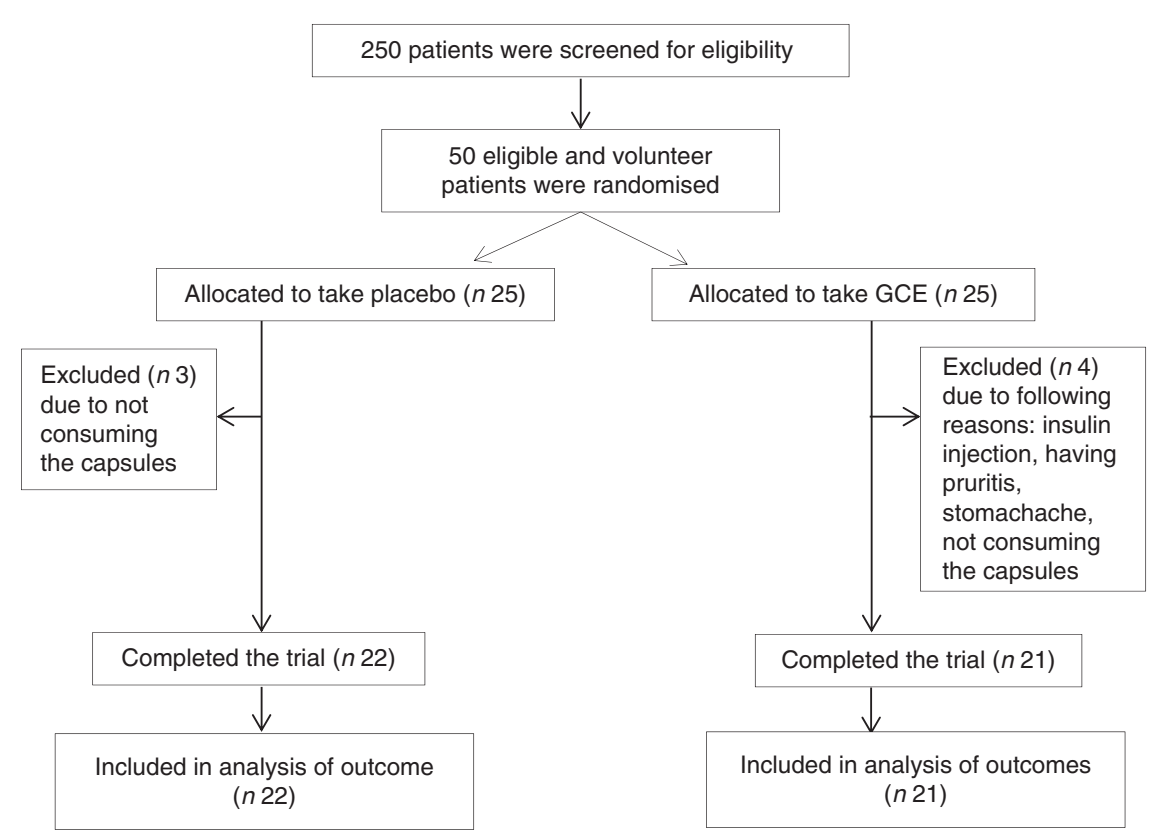

Fig. 1. Flow chart of study participants. GCE, green coffee extract. 
v. $10 \cdot 12(\mathrm{sD} 4.55) \mu \mathrm{IU} / \mathrm{ml})(P=0 \cdot 006)$. Also, fasting insulin after GCE consumption was significantly $29 \%$ less than the placebo group at the end of the study (10.12 (SD 4.55) $v .14 \cdot 20$ (SD 7.44) $\mu \mathrm{IU} /$ $\mathrm{ml})(P=0 \cdot 03)$. In addition, a significant difference existed between

Table 2. Baseline characteristics of participants in both study groups (Numbers and percentages; mean values and standard deviations)

\begin{tabular}{|c|c|c|c|c|c|}
\hline \multirow[b]{2}{*}{ Baseline variables } & \multicolumn{2}{|c|}{$\begin{array}{c}\text { GCE group } \\
(n 21)\end{array}$} & \multicolumn{2}{|c|}{$\begin{array}{c}\text { Placebo } \\
\text { group }(n 22)\end{array}$} & \multirow[b]{2}{*}{$P^{\star}$} \\
\hline & $n$ & $\%$ & $n$ & $\%$ & \\
\hline \multicolumn{6}{|l|}{ Sex } \\
\hline Female & 17 & 81 & 16 & $72 \cdot 7$ & \multirow[t]{2}{*}{0.52} \\
\hline Male & 4 & 19 & 6 & $27 \cdot 3$ & \\
\hline \multicolumn{6}{|l|}{ Smoking status } \\
\hline Yes & 2 & 9.5 & 1 & 4.5 & \multirow[t]{2}{*}{0.52} \\
\hline No & 19 & 90.5 & 21 & $95 \cdot 5$ & \\
\hline \multicolumn{6}{|l|}{ Oral hypoglycaemia drugs } \\
\hline Biguanides & 19 & 90.5 & 15 & $68 \cdot 2$ & 0.07 \\
\hline Sulfonylureas & 7 & 33.3 & 9 & $40 \cdot \overline{9}$ & 0.60 \\
\hline$a$-Glucosidase inhibitors & 4 & 19 & 3 & 19.6 & 0.63 \\
\hline Other & 1 & 4.8 & 0 & 0 & 0.30 \\
\hline None & 2 & 9.5 & 7 & 31.8 & 0.07 \\
\hline \multicolumn{6}{|l|}{ Lipid-lowering drugs } \\
\hline Statins & 12 & $57 \cdot 1$ & 13 & $59 \cdot 1$ & \multirow[t]{2}{*}{0.89} \\
\hline None & 9 & $42 \cdot 9$ & 9 & 49.9 & \\
\hline \multicolumn{6}{|l|}{ Anti-hypertensive drugs } \\
\hline Angiotensin II receptor antagonists & 7 & 33.3 & 5 & $22 \cdot 7$ & 0.43 \\
\hline ACE inhibitors & 2 & 9.5 & 3 & $13 \cdot 6$ & 0.67 \\
\hline Diuretics & 1 & 4.8 & 2 & $9 \cdot 1$ & 0.57 \\
\hline Beta blockers & 3 & $14 \cdot 3$ & 5 & $22 \cdot 7$ & 0.47 \\
\hline Other & 1 & 4.8 & 1 & 4.5 & 0.97 \\
\hline None & 10 & $45 \cdot 4$ & 9 & $42 \cdot 8$ & 0.65 \\
\hline \multicolumn{6}{|l|}{ Menopause status } \\
\hline Yes & 12 & 57 & 10 & 45 & \multirow[t]{2}{*}{0.72} \\
\hline No & 5 & 23 & 6 & 27 & \\
\hline \multicolumn{6}{|l|}{ Age (years) } \\
\hline Mean & \multirow{2}{*}{\multicolumn{2}{|c|}{$\begin{array}{c}52.76 \\
9.83\end{array}$}} & \multirow{2}{*}{\multicolumn{2}{|c|}{$\begin{array}{c}51.95 \\
8.67\end{array}$}} & \multirow[t]{2}{*}{0.77} \\
\hline SD & & & & & \\
\hline \multicolumn{6}{|l|}{ Duration of diabetes (years) } \\
\hline Mean & \multirow{2}{*}{\multicolumn{2}{|c|}{$\begin{array}{l}3.83 \\
4.19\end{array}$}} & \multirow{2}{*}{\multicolumn{2}{|c|}{$\begin{array}{l}3.28 \\
4.29\end{array}$}} & 0.67 \\
\hline SD & & & & & \\
\hline
\end{tabular}

GCE, green coffee extract; ACE inhibitors; angiotensin-converting enzyme inhibitors. ${ }^{*} P$ values are for comparison of the variables between the two groups (all by $x^{2}$ test, except for age and duration of diabetes which were analysed by independent $t$ test). the two groups concerning HOMA-IR index changes $(-1 \cdot 41$ (SD 3.33) v. 1.23 (SD 3.84)) ( $P=0.02$ ) (effect size: -0.73 ; $95 \%$ CI -1.35 , $-0 \cdot 11$ ). Nonetheless, HbA1c percentage did not differ between and within the groups after conducting the trial.

A significant reduction was observed in waist circumference of the participants who had consumed GCE compared with the placebo group $(-2.40(\mathrm{sD} 2.54) v .-0.66(\mathrm{sD} 1 \cdot 17) \mathrm{cm})(P=0.009)$ (effect size: $-0.88 ; 95 \% \mathrm{CI}-1 \cdot 51,-0 \cdot 26$ ). The post-trial mean weight and BMI of the patients had significantly decreased $v$. the pre-trial values by $2.5 \%$ within the intervention group (weight: $P=0.00$, BMI: $P=0.00$ ) and by $1 \%$ within the placebo group (weight: $P=0 \cdot 009$, BMI: $P=0 \cdot 011$ ). Hence, weight and BMI of the subjects consuming GCE had reduced almost twice as much as individuals consuming placebo capsules; however, this difference between the two groups was marginally significant (weight: -2.08 (sD 2.11) v. $-0.92(\mathrm{sD} 1.30) \mathrm{kg}, P=0.05)$ (BMI: -0.84 (SD 0.86) $v .-0.37$ (sD 0.52$\left.) \mathrm{kg} / \mathrm{m}^{2}, P=0.05\right)$ (effect size: $-0 \cdot 66 ; 95 \% \mathrm{CI}-1 \cdot 27,-0 \cdot 05)$.

No significant discrepancy was observed in terms of lipid profile parameters consisted of serum TAG, TC, LDL-cholesterol and HDL-cholesterol concentrations between and within the groups after conducting the trial.

Appetite score analysis revealed that appetite level of the subjects who had consumed GCE had significantly attenuated in relation to the participants who had taken placebo capsules $(-1.44$ (sD 1.72) v. $-0.2($ sD 1.32)) $(P=0.02)$ (effect size: $-0 \cdot 81$; $95 \% \mathrm{CI}-1 \cdot 43,-0 \cdot 18)$. Appetite score alterations within the GCEadministered group were also significant as the post-trial scores were $9.6 \%$ lower than the baseline (15.06 (SD 1.51) v. 13.61 (sD 1.53)) $(P=0.002)$.

\section{Discussion}

The present clinical trial was carried out to examine the effects of $800 \mathrm{mg} / \mathrm{d}$ of GCE supplementation for 8 weeks in patients with the Mets. A significant reduction was observed regarding SBP, FBS, HOMA-IR, waist circumference and appetite score after GCE administration compared with the placebo. Also, post-trial DBP

Table 3. Dietary intakes and physical activity of the participants during the trial (Mean values and standard deviations)

\begin{tabular}{|c|c|c|c|c|c|c|c|c|c|c|c|c|c|c|c|}
\hline & \multicolumn{6}{|c|}{ GCE group ( $n$ 21) } & \multicolumn{6}{|c|}{ Placebo group ( $n$ 22) } & \multirow[b]{3}{*}{$P^{\star}$} & \multirow[b]{3}{*}{$P \dagger$} & \multirow[b]{3}{*}{$P \ddagger$} \\
\hline & \multicolumn{2}{|c|}{ Baseline } & \multicolumn{2}{|c|}{4 weeks } & \multicolumn{2}{|c|}{8 weeks } & \multicolumn{2}{|c|}{ Baseline } & \multicolumn{2}{|c|}{4 weeks } & \multicolumn{2}{|c|}{8 weeks } & & & \\
\hline & Mean & SD & Mean & SD & Mean & SD & Mean & SD & Mean & SD & Mean & SD & & & \\
\hline Energy (kJ/d) & 6698.6 & $2146 \cdot 4$ & 6932.9 & 1853.5 & 6338.8 & 1514.6 & $7079 \cdot 3$ & $1514 \cdot 6$ & 6673.5 & $1698 \cdot 7$ & 6389 & $1774 \cdot 0$ & 0.50 & 0.63 & 0.92 \\
\hline Energy $(\mathrm{kcal} / \mathrm{d})$ & $1601 \cdot 0$ & $513 \cdot 0$ & $1657 \cdot 0$ & $443 \cdot 0$ & $1515 \cdot 0$ & $362 \cdot 0$ & $1692 \cdot 0$ & $362 \cdot 0$ & $1595 \cdot 0$ & $406 \cdot 0$ & $1527 \cdot 0$ & $424 \cdot 0$ & 0.50 & 0.63 & 0.92 \\
\hline Carbohydrate $(\mathrm{g} / \mathrm{d})$ & $213 \cdot 1$ & 61.6 & 218.6 & 67.9 & $215 \cdot 1$ & 70.5 & $230 \cdot 1$ & $74 \cdot 1$ & 233.0 & $77 \cdot 3$ & $216 \cdot 2$ & 91.0 & 0.42 & 0.51 & 0.96 \\
\hline Protein $(\mathrm{g} / \mathrm{d})$ & $52 \cdot 4$ & $18 \cdot 1$ & $58 \cdot 8$ & $26 \cdot 8$ & $56 \cdot 4$ & $15 \cdot 8$ & $59 \cdot 3$ & $16 \cdot 6$ & 63.2 & $16 \cdot 4$ & 58.0 & $16 \cdot 4$ & 0.20 & 0.51 & 0.74 \\
\hline Fat $(g / d)$ & $50 \cdot 4$ & $20 \cdot 8$ & 54.6 & $20 \cdot 7$ & 47.4 & $18 \cdot 9$ & 48.9 & $12 \cdot 7$ & $46 \cdot 4$ & $12 \cdot 1$ & $46 \cdot 4$ & $15 \cdot 1$ & 0.78 & 0.12 & 0.84 \\
\hline Fibre $(g / d)$ & 11.5 & 5.5 & $12 \cdot 2$ & $6 \cdot 4$ & $12 \cdot 7$ & 4.0 & $13 \cdot 1$ & 4.8 & 14.7 & 4.8 & $13 \cdot 3$ & 6.5 & 0.31 & 0.15 & 0.16 \\
\hline $\mathrm{Ca}(\mathrm{mg} / \mathrm{d})$ & $508 \cdot 0$ & 243.0 & $524 \cdot 0$ & $267 \cdot 0$ & $625 \cdot 0$ & $375 \cdot 0$ & $532 \cdot 0$ & $288 \cdot 0$ & $602 \cdot 0$ & $280 \cdot 0$ & $515 \cdot 0$ & $326 \cdot 0$ & 0.76 & 0.35 & 0.31 \\
\hline$M g(\mathrm{mg} / \mathrm{d})$ & $152 \cdot 3$ & 49.1 & 159.3 & 52.4 & $161 \cdot 2$ & 52.9 & $173 \cdot 9$ & $46 \cdot 1$ & $180 \cdot 5$ & $43 \cdot 1$ & $230 \cdot 7$ & $238 \cdot 3$ & 0.14 & 0.15 & 0.19 \\
\hline $\mathrm{K}(\mathrm{mg} / \mathrm{d})$ & $1799 \cdot 7$ & 559.1 & 1828 & 538.8 & 1847.5 & 507.5 & $2098 \cdot 4$ & $530 \cdot 2$ & $2216 \cdot 4$ & 581.0 & $2250 \cdot 4$ & 814.5 & 0.08 & 0.05 & 0.06 \\
\hline Physical activity (MET-h/d) & 38.06 & 4.59 & - & - & $38 \cdot 21$ & $3 \cdot 32$ & $40 \cdot 25$ & 4.48 & - & - & 38.92 & 4.97 & 0.12 & - & 0.58 \\
\hline
\end{tabular}

GCE, green coffee extract; MET, metabolic equivalent of task.

${ }^{*} P$ values are for comparison between the two groups at baseline (independent $t$ test).

t $P$ values are for comparison between the two groups after 4 weeks (independent $t$ test).

$\ddagger P$ values are for comparison between the two groups after 8 weeks (independent $t$ test). 
Table 4. Dependent variables before and after the study and their changes throughout the trial in both groups before and after the study (Mean values and standard deviations; effect sizes and 95\% confidence intervals)

\begin{tabular}{|c|c|c|c|c|c|c|c|c|c|c|}
\hline & \multicolumn{2}{|c|}{ Baseline } & \multicolumn{2}{|c|}{ After 8 weeks } & \multirow[b]{2}{*}{$P^{*}$} & \multicolumn{2}{|c|}{ Changes } & \multirow[b]{2}{*}{$P \dagger$} & \multirow[b]{2}{*}{ Effect sizeł } & \multirow[b]{2}{*}{$95 \% \mathrm{Cl} \ddagger$} \\
\hline & Mean & SD & Mean & SD & & Mean & SD & & & \\
\hline \multicolumn{11}{|c|}{$\mathrm{SBP}(\mathrm{mmHg})$} \\
\hline GCE§ & \multirow{2}{*}{$\begin{array}{l}140 \cdot 57 \\
140 \cdot 90\end{array}$} & 17.95 & $126 \cdot 80$ & $16 \cdot 53$ & \multirow[t]{2}{*}{0.143} & $-13 \cdot 76$ & 8.48 & \multirow[t]{2}{*}{0.013} & \multirow[t]{2}{*}{-0.79} & \multirow[t]{2}{*}{$-1.41,-0.17$} \\
\hline Placebo§ & & 17.51 & 134.34 & 16.54 & & -6.56 & 9.58 & & & \\
\hline \multicolumn{11}{|c|}{$\mathrm{DBP}(\mathrm{mmHg})$} \\
\hline GCE & $80 \cdot 80$ & 9.56 & 77.02 & 7.88 & \multirow[t]{2}{*}{0.037} & -3.78 & 7.30 & \multirow[t]{2}{*}{0.534} & \multirow[t]{2}{*}{0.18} & $-0.41,0.78$ \\
\hline Placebo & 89.50 & $18 \cdot 61$ & 83.36 & 11.02 & & -6.13 & $15 \cdot 84$ & & & \\
\hline FBS (mmol & & & & & & & & & & \\
\hline GCE & 8.38 & 4.04 & $8 \cdot 10$ & $2 \cdot 21$ & 0.377 & -0.28 & 3.34 & 0.036 & -0.67 & $-1.29,-0.06$ \\
\hline Placebo & $7 \cdot 27$ & 1.69 & 8.90 & 3.39 & & 1.63 & $2 \cdot 22$ & & & \\
\hline Insulin $(\mu \mathrm{IU}$ & & & & & & & & & & \\
\hline GCE & 12.94 & 5.96 & $10 \cdot 12$ & 4.55 & 0.037 & -2.82 & $4 \cdot 20$ & 0.105 & -0.44 & $-1.04,0.16$ \\
\hline Placebo & 14.29 & 4.83 & $14 \cdot 20$ & 7.44 & & -0.39 & $6 \cdot 46$ & & & \\
\hline HOMA-IR & & & & & & & & & & \\
\hline GCE & 5.04 & 3.95 & 3.62 & 1.83 & 0.065 & -1.41 & 3.33 & 0.024 & -0.73 & $-1.35,-0.11$ \\
\hline Placebo & $4 \cdot 71$ & 2.55 & 5.94 & $5 \cdot 16$ & & 1.23 & 3.84 & & & \\
\hline HbA1c (\%; & & & & & & & & & & \\
\hline GCE & $7 \cdot 42$ & 1.28 & $7 \cdot 33$ & 0.95 & 0.572 & -0.09 & 1.34 & 0.927 & -0.03 & $-0.63,0.56$ \\
\hline Placebo & $7 \cdot 18$ & 1.21 & $7 \cdot 12$ & 1.30 & & -0.05 & $1 \cdot 14$ & & & \\
\hline WC (cm) & & & & & & & & & & \\
\hline GCE & $106 \cdot 40$ & 9.73 & $104 \cdot 0$ & 8.82 & 0.195 & -2.40 & 2.54 & 0.009 & -0.88 & $-1.51,-0.26$ \\
\hline Placebo & 108.66 & $10 \cdot 43$ & 108.0 & $10 \cdot 12$ & & -0.66 & $1 \cdot 17$ & & & \\
\hline Weight (kg) & & & & & & & & & & \\
\hline GCE & $78 \cdot 10$ & 11.01 & 76.01 & $10 \cdot 52$ & 0.408 & -2.08 & $2 \cdot 11$ & 0.057 & -0.66 & $-1.27,-0.05$ \\
\hline Placebo & $80 \cdot 11$ & 12.45 & $79 \cdot 18$ & $12 \cdot 75$ & & -0.92 & 1.30 & & & \\
\hline BMI $\left(\mathrm{kg} / \mathrm{m}^{2}\right.$ & & & & & & & & & & \\
\hline GCE & 31.60 & 3.58 & $30 \cdot 76$ & 3.36 & 0.572 & -0.84 & 0.86 & 0.055 & -0.66 & $-1.27,-0.05$ \\
\hline Placebo & $31 \cdot 16$ & 4.88 & $30 \cdot 79$ & 4.93 & & -0.37 & 0.52 & & & \\
\hline TAG (mmol & & & & & & & & & & \\
\hline GCE & $2 \cdot 36$ & 0.95 & $2 \cdot 11$ & 0.65 & 0.578 & -0.07 & 0.60 & 0.439 & 0.24 & $-0.35,0.84$ \\
\hline Placebo & 2.05 & 0.75 & 1.98 & 0.78 & & -0.25 & 0.87 & & & \\
\hline $\mathrm{TC}(\mathrm{mmol} / \mathrm{l})$ & & & & & & & & & & \\
\hline GCE & 4.59 & 1.05 & 4.64 & 1.00 & 0.624 & 0.04 & 1.02 & 0.998 & 0.0009 & $-0.59,0.59$ \\
\hline Placebo & 4.42 & $1 \cdot 15$ & $4 \cdot 47$ & $1 \cdot 19$ & & 0.04 & 0.72 & & & \\
\hline HDL-choles & & & & & & & & & & \\
\hline GCE & $1 \cdot 17$ & 0.17 & 1.23 & 0.26 & 0.554 & 0.05 & 0.22 & 0.923 & 0.03 & $-0.56,0.63$ \\
\hline Placebo & $1 \cdot 13$ & $0 \cdot 12$ & 1.19 & $0 \cdot 16$ & & 0.05 & 0.09 & & & \\
\hline LDL-choles & & & & & & & & & & \\
\hline GCE & $2 \cdot 32$ & 0.88 & $2 \cdot 43$ & 0.85 & 0.331 & 0.10 & 0.47 & 0.992 & 0.003 & $-0.59,0.60$ \\
\hline Placebo & 2.08 & 0.55 & $2 \cdot 19$ & 0.64 & & $0 \cdot 10$ & 0.77 & & & \\
\hline Appetite sc & & & & & & & & & & \\
\hline GCE & $15 \cdot 06$ & 1.51 & 13.61 & 1.53 & 0.292 & -1.44 & 1.72 & 0.017 & -0.81 & $-1.43,-0.18$ \\
\hline Placebo & 14.40 & $1 \cdot 75$ & $14 \cdot 20$ & 1.82 & & -0.2 & 1.32 & & & \\
\hline
\end{tabular}

SBP, systolic blood pressure; GCE, green coffee extract; WC, waist circumference; DBP, diastolic blood pressure; FBS, fasting blood sugar; HOMA-IR, homoeostatic model assessment of insulin resistance; $\mathrm{HbA1c}$, glycated $\mathrm{Hb}$; TC, total cholesterol.

* $P$ values are for comparison between the two groups after the intervention (independent $t$ test).

$\dagger P$ values are for comparison of changes of each variable between the two groups (independent $t$ test).

$\mp$ Cohen's $d$ effect sizes and their $95 \% \mathrm{Cl}$ are displayed for changes of variables during the study.

$\S$ Total $n$ for GCE group and placebo group were 21 and 22 subjects, respectively.

॥ To convert insulin in $\mu \mathrm{lU} / \mathrm{ml}$ to pmol/l, multiply by 6.945 . To convert TAG, cholesterol and glucose in $\mathrm{mmol} / \mathrm{l}$ to $\mathrm{mg} / \mathrm{dl}$, divide by $0.0113,0.0259$ and 0.0555 , respectively.

and insulin values were lower in the GCE group. Moreover, weight loss and BMI reduction after GCE consumption was about twice as much as the placebo group; however, this discrepancy was marginally significant. GCE had no significant impact on lipid profile parameters and HBA1c.

The GCE dose used in our trial provided $372 \mathrm{mg}$ of CGA/d. This amount of CGA can be achievable in the diet through coffee consumption. It has been estimated that coffee drinkers may have daily intake of $0.5-1.0 \mathrm{~g} \mathrm{CGA} / \mathrm{d}^{(16)}$. Each $1 \mathrm{~g}$ of dry Arabica or Robusta GC bean has been reported to provide 68.8 and $88 \mathrm{mg}$ of CGA, respectively ${ }^{(9)}$.

Our findings regarding SBP and DBP reduction with GCE are concurrent with previous studies. A trial on twenty-eight patients with mild hypertension who received $125 \mathrm{ml} / \mathrm{d}$ of a juice with $0.48 \mathrm{~g}$ GCE (containing $140 \mathrm{mg}$ CGA) for 12 weeks indicated a significant decline in SBP and DBP compared with the group taking placebo juice ${ }^{(21)}$. In another clinical trial on 117 mildly hypertensive males, SBP and DBP significantly reduced after consuming 93 or $185 \mathrm{mg}$ GCE for $28 \mathrm{~d}$ in relation to placebo ${ }^{(22)}$. Also, a cross-over study ${ }^{(20)}$ which compared intake of $40 \mathrm{~g}$ GC with $40 \mathrm{~g}$ black coffee, each taken for 2 weeks, revealed a significant reduction in SBP after GC intake compared with black coffee. However, DBP reduced after ingestion of both coffees. Meanwhile, GC could decrease urinary cortisol levels in this study by $39 \%$. It has been postulated that CGA inhibits $11 \beta$-hydroxysteroid dehydrogenase 
which converts cortisone to active cortisol. Cortisol is capable of increasing blood pressure by reducing production and bioavailability of nitric oxide, increasing sensitivity to vasoconstrictors such as endothelin and triggering $\mathrm{Na}$ absorption in kidneys to retain water. Hence, the hypotensive feature of GC could be attributed to its cortisol-lowering effect ${ }^{(20)}$

Moreover, GCE in our study was capable of mildly reducing FBS and suppressing its increase compared with placebo. This is consistent with other studies. For instance, Song et al. ${ }^{(24)}$ examined DGCE impact on mice fed a HFD diet with $0 \cdot 1,0.3$ or $0.9 \%$ GCE. The group with $0.3 \%$ GCE $(300 \mathrm{mg} / \mathrm{kg}$ diet equivalent to $1460 \mathrm{mg} / 60 \mathrm{~kg}$ for humans) plus the HFD diet indicated a significant decline in FBS compared with the HFD group after 11 weeks. Another study on diabetic rats compared GC effects with light and dark roasted coffee. It was observed that GC had the best effect on attenuating glucose level ${ }^{(7)}$. Also, a recent animal study displayed a significant decrease in FBS with $100 \mathrm{mg} / \mathrm{kg}$ GCE plus HFD diet in comparison to the HFD group after 6 weeks ${ }^{(23)}$. The mechanism by which corresponds to lowering FBS by CGA is activation of AMP-activated protein kinase (AMPK). Activation of AMPK contributes to increasing GLUT4 translocation to plasma membrane which augments glucose transport to cells and leads to peripheral glucose disposal ${ }^{(34)}$. Also, CGA in GCE can inhibit glucose6-phosphatase (Glc-6-pase) by 36\% leading to limited glucose production by gluconeogenesis and glycogenolysis ${ }^{(35)}$. Our results also revealed that GCE supplementation significantly lowered HOMA-IR index and consequently abated insulin resistance. This has been corroborated by some of previous studies. In one study, $80 \mathrm{mg} / \mathrm{kg}$ of DGCE for 14 weeks resulted in improvement of HFD-induced insulin resistance in mice ${ }^{(25)}$. Also, $0.3 \%$ DGCE plus HFD for 11 weeks led to attenuation of HOMA-IR values in mice compared with a control group ${ }^{(24)}$. Nevertheless, one study conducted on the Mets model of mice did not detect any improvement in insulin resistance in mice fed a HFD diet with $0.5 \%(\mathrm{w} / \mathrm{w})$ GCE for 12 weeks $^{(19)}$. It has been proposed by Song et al. ${ }^{(24)}$ that GCE exerts its ameliorating effect on insulin resistance by decreasing phosphorylation of c-Jun N-terminal kinase which leads to activation of insulin receptor substrate-1 resulting in GLUT4 translocation to adipocyte membrane and increasing insulin sensitivity.

Our GCE treatment was not effective in reducing HbA1c percentage. On the contrary, in one study it was observed that $80 \mathrm{mg} / \mathrm{kg}$ per d of CGA administration for 12 weeks decreased HbA1c along with FBS in $\mathrm{db} / \mathrm{db}$ mice by modulating adiponectin receptor signalling pathways ${ }^{(36)}$. As the mentioned study appraised solely CGA's effect on HbA1c, its results might be dissimilar with our study which explored GCE effects. Also, lipid profile parameters in our trial were not improved using GCE. This finding is concordant with some studies. For instance, in the aforementioned study examining GCE effects on HFD-induced the Mets model of mice for 12 weeks, GCE did not affect lipid profile $^{(19)}$. Likewise, $0.48 \mathrm{~g}$ GCE providing $140 \mathrm{mg}$ CGA/d for 12 weeks did not yield any improvement in lipid profile ${ }^{(21)}$. However, some animal studies have shown positive effects. For example, in HFD-induced obese mice $200 \mathrm{mg} / \mathrm{kg}$ GCE plus HFD for 4 weeks could decrease TC, TAG and LDL-cholesterol while increasing HDL-cholesterol level compared with a HFD group ${ }^{(23)}$.
Our study demonstrated that GCE could decrease weight and BMI about twice as much as the placebo; however, this difference was marginally significant. Furthermore, GCE in our study was capable of significantly reducing waist circumference compared with the placebo. Weight loss recommendations were given to both groups. Thus, this difference is attributed to GCE consumption. Some other studies have shown anti-obesity property of GCE. In a pilot clinical study on fifteen patients, $600 \mathrm{mg}$ of DGCE for $40 \mathrm{~d}$ resulted in $1.36 \mathrm{~kg}$ weight loss ${ }^{(28)}$. The aforementioned crossover study comparing $40 \mathrm{~g} / \mathrm{d}$ of black and GC, which is eight times more than the amount of GC used in our study, demonstrated a significant reduction of $1.4 \mathrm{~kg}$ in weight and $0.28 \mathrm{~kg} / \mathrm{m}^{2}$ in BMI with GC after 2 weeks. Waist circumference and abdominal fat also decreased after both interventions. However, these effects may be partially due to caffeine aside from $\mathrm{CGA}^{(20)}$. Also, a clinical trial conducted on thirty overweight patients detected a significant attenuation in weight after 12 weeks of consuming $11 \mathrm{~g} \mathrm{GCE-}$ enriched coffee providing $1000 \mathrm{mg}$ GCE and $500 \mathrm{mg}$ CGA/d compared with an instant coffee group (5.4 (SD 0.6) kg $v \cdot 1.7$ (sD 0.9) kg). The greater weight loss in this trial compared with our study might be due to the higher dose of GCE consumed ${ }^{(16)}$. In a recent study on HFD-induced obese mice 100 or $200 \mathrm{mg} / \mathrm{kg} \mathrm{GCE}$ for 4 weeks plus HFD significantly reduced weight and body fat compared with the HFD group ${ }^{(23)}$. However, $0.5 \%$ (w/w) GCE plus HFD in a mouse model of the Mets could not lead to losing weight after 12 weeks $^{(19)}$. It has been assumed by Song et al. that GCE exerts its weight-lowering effects by inhibiting adipogenesis which is mainly regulated by transcription factors such as PPAR $\gamma 2$. This was corroborated by down-regulation of adipogenic target genes of PPAR $\gamma 2$ such as adipocyte lipid binding protein, cluster of differentiation 36, fatty acid synthase and lipoprotein lipase by $\mathrm{GCE}^{(24)}$. Also, inhibition of Glc-6-pase by GCE which leads to decreased glucose release by glycogenolysis, makes lipids to be utilised as energy source ${ }^{(35)}$. Furthermore, our study for the first time unveiled that GCE consumption contributes to controlling appetite which can ultimately lead to losing weight.

Limitations of our study encompass, first, the short time of the trial. Second, we did not have access to professional scales and a body composition analyser to assess alterations in body fat percentage. Third, due to budget deficit, measuring other factors such as appetite-related hormones was not possible. Further studies with longer durations and larger sample sizes are required to establish potential GCE effects in patients with the Mets.

\section{Conclusion}

In conclusion, the GCE in this trial could attenuate SBP, FBS, HOMA-IR, waist circumference and appetite in comparison to the placebo in patients with the Mets. Hence, GC extract supplementation could feasibly be an effective approach for management of some of the Mets features and Mets major causes such as insulin resistance and abdominal obesity.

\section{Acknowledgements}

The authors express their gratitude to the subjects for their participation in this research and the Arjuna Natural Extracts Ltd for generously providing the supplements. 
This study was financially supported by a grant from the National Nutrition and Food Technology Research Institute of Shahid Beheshti University (G. S., grant no. 655). The GCE and placebo capsules were provided by Arjuna Natural Extracts Ltd as a donation. The funders had no role in the design, analysis or writing of this article.

G. S., H. R. and O. N. designed the study. M. S. contributed to diagnosing and referring the patients with the metabolic syndrome. H. R. and O. N. carried out the trial and followed the patients. H. R analysed the data and wrote the article.

The authors declare that there are no conflicts of interest.

\section{References}

1. Kaur J (2014) A comprehensive review on metabolic syndrome. Cardiol Res Pract 2014, 943162.

2. Takami H, Nakamoto M, Uemura H, et al. (2013) Inverse correlation between coffee consumption and prevalence of metabolic syndrome: baseline survey of the Japan Multi-Institutional Collaborative Cohort (J-MICC) Study in Tokushima, Japan. J Epidemiol 23, 12-20.

3. International Diabetes Federation (2006) The IDF consensus worldwide definition of the metabolic syndrome. https:// www.idf.org/e-library/consensus-statements/60-idfconsensusworldwide-definitionof-the-metabolic-syndrome.html (accessed November 2017).

4. Razavi BM \& Hosseinzadeh H (2017) Saffron: a promising natural medicine in the treatment of metabolic syndrome. J Sci Food Agric 97, 1679-1685.

5. Santana-Galvez J, Cisneros-Zevallos L \& Jacobo-Velazquez DA (2017) Chlorogenic acid: recent advances on its dual role as a food additive and a nutraceutical against metabolic syndrome. Molecules 22, 358

6. Shang F, Li X \& Jiang X (2016) Coffee consumption and risk of the metabolic syndrome: a meta-analysis. Diabetes Metab $\mathbf{4 2}$, 80-87.

7. Ahmed GM, El-Ghamery HE \& Samy MF (2013) Effect of green and degree of roasted Arabic coffee on hyperlipidemia and antioxidant status in diabetic rats. Adv J Food Sci Technol 5, 619-626.

8. Meng S, Cao J, Feng Q, et al. (2013) Roles of chlorogenic acid on regulating glucose and lipids metabolism: a review. Evid Based Complement Alternat Med 2013, 801457.

9. Upadhyay R \& Mohan Rao LJ (2013) An outlook on chlorogenic acids-occurrence, chemistry, technology, and biological activities. Crit Rev Food Sci Nutr 53, 968-984.

10. Ludwig IA, Mena P, Calani L, et al. (2014) Variations in caffeine and chlorogenic acid contents of coffees: what are we drinking? Food Funct 5, 1718-1726.

11. Cho AS, Jeon SM, Kim MJ, et al. (2010) Chlorogenic acid exhibits anti-obesity property and improves lipid metabolism in high-fat diet-induced-obese mice. Food Chem Toxicol 48, 937-943.

12. Ong KW, Hsu A \& Tan BK (2013) Anti-diabetic and antilipidemic effects of chlorogenic acid are mediated by ampk activation. Biochem Pharmacol 85, 1341-1351.

13. Ma Y, Gao M \& Liu D (2015) Chlorogenic acid improves high fat diet-induced hepatic steatosis and insulin resistance in mice. Pharm Res 32, 1200-1209.

14. Onakpoya IJ, Spencer EA, Thompson MJ, et al. (2015) The effect of chlorogenic acid on blood pressure: a systematic review and meta-analysis of randomized clinical trials. J Hum Hypertens 29, 77-81.

15. Mubarak A, Bondonno CP, Liu AH, et al. (2012) Acute effects of chlorogenic acid on nitric oxide status, endothelial function, and blood pressure in healthy volunteers: a randomized trial. J Agric Food Chem 60, 9130-9136.

16. Thom E (2007) The effect of chlorogenic acid enriched coffee on glucose absorption in healthy volunteers and its effect on body mass when used long-term in overweight and obese people. J Int Med Res 35, 900-908.

17. Sarriá B, Martínez-López S, Sierra-Cinos JL, et al. (2016) Regularly consuming a green/roasted coffee blend reduces the risk of metabolic syndrome. Eur J Nutr (Epublication ahead of print version 13 October 2016).

18. Varghese M, Ho L, Wang J, et al. (2014) Green coffee as a novel agent for Alzheimer's disease prevention by attenuating diabetes. Transl Neurosci 5, 111-116.

19. Li Kwok Cheong JD, Croft KD, Henry PD, et al. (2014) Green coffee polyphenols do not attenuate features of the metabolic syndrome and improve endothelial function in mice fed a high fat diet. Arch Biochem Biophys 559, 46-52.

20. Revuelta-Iniesta R \& Al-Dujaili EA (2014) Consumption of green coffee reduces blood pressure and body composition by influencing 11beta-HSD1 enzyme activity in healthy individuals: a pilot crossover study using green and black coffee. Biomed Res Int 2014, 482704.

21. Watanabe T, Arai Y, Mitsui Y, et al. (2006) The blood pressure-lowering effect and safety of chlorogenic acid from green coffee bean extract in essential hypertension. Clin Exp Hypertens 28, 439-449.

22. Kozuma K, Tsuchiya S, Kohori J, et al. (2005) Antihypertensive effect of green coffee bean extract on mildly hypertensive subjects. Hypertens Res 28, 711-718.

23. Choi BK, Park SB, Lee DR, et al. (2016) Green coffee bean extract improves obesity by decreasing body fat in high-fat diet-induced obese mice. Asian Pac J Trop Med 9 , 635-643.

24. Song SJ, Choi S \& Park T (2014) Decaffeinated green coffee bean extract attenuates diet-induced obesity and insulin resistance in mice. Evid Based Complement Alternat Med 2014, 718379

25. Ho L, Varghese M, Wang J, et al. (2012) Dietary supplementation with decaffeinated green coffee improves dietinduced insulin resistance and brain energy metabolism in mice. Nutr Neurosci 15, 37-45.

26. Dellalibera O, Lemaire B \& Lafay S (2006) Svetol®, green coffee extract, induces weight loss and increases the lean to fat mass ratio in volunteers with overweight problem. Phytotherapie 4, 194-197.

27. Shimoda H, Seki E \& Aitani M (2006) Inhibitory effect of green coffee bean extract on fat accumulation and body weight gain in mice. BMC Complement Altern Med 6, 9.

28. Blum J, Lemaire B \& Lafay S (2007) Effect of a green decaffeinated coffee extract on glycaemia: a pilot prospective clinical study. NutraFoods 6, 13-17.

29. Ghaffarpour M, Houshiar-Rad A \& Kianfar H (1999) The Manual for Housebold Measures, Cooking Yields Factors and Edible Portion of Foods. Tehran: Nashre Olume Keshavarzy.

30. Ainsworth BE, Haskell WL, Whitt MC, et al. (2000) Compendium of physical activities: an update of activity codes and MET intensities. Med Sci Sports Exerc 32, S498-S504.

31. Wilson MM, Thomas DR, Rubenstein LZ, et al. (2005) Appetite assessment: simple appetite questionnaire predicts weight loss in community-dwelling adults and nursing home residents. Am J Clin Nutr 82, 1074-1081.

32. Matthews DR, Hosker JP, Rudenski AS, et al. (1985) Homeostasis model assessment: insulin resistance and beta-cell function from fasting plasma glucose and insulin concentrations in man. Diabetologia 28, 412-419. 
33. Ebrahimi M, Ghayour-Mobarhan M, Rezaiean S, et al. (2009) Omega-3 fatty acid supplements improve the cardiovascular risk profile of subjects with metabolic syndrome, including markers of inflammation and auto-immunity. Acta Cardiol 64, 321-327.

34. Ong KW, Hsu A \& Tan BK (2012) Chlorogenic acid stimulates glucose transport in skeletal muscle via AMPK activation: a contributor to the beneficial effects of coffee on diabetes. PLOS ONE 7, e32718.
35. Henry-Vitrac C, Ibarra A, Roller M, et al. (2010) Contribution of chlorogenic acids to the inhibition of human hepatic glucose6-phosphatase activity in vitro by Svetol, a standardized decaffeinated green coffee extract. J Agric Food Chem 58, 4141-4144.

36. Jin S, Chang C, Zhang L, et al. (2015) Chlorogenic acid improves late diabetes through adiponectin receptor signaling pathways in $\mathrm{db} / \mathrm{db}$ mice. PLOS ONE 10, e0120842. 